Paidéia, 2005, 15(32), 377-385

\title{
RELATOS DE VIOLÊNCIA, CONCEPÇÕES DE VIOLÊNCIA E PRÁTICAS ESCOLARES DE PROFESSORAS: EM BUSCA DE RELAÇÕES ${ }^{1}$
}

\author{
Liliane Viana de Souza ${ }^{2}$ \\ Marilena Ristum \\ Universidade Federal da Bahia
}

\begin{abstract}
Resumo: Dando continuidade a um estudo sobre concepções de violência e práticas docentes, esse estudo objetivou: analisar os relatos de episódios de violência vivenciados por professoras; relacionar os relatos ao conceito de violência dessas professoras e também às suas práticas em sala de aula e, finalmente, comparar professoras de escolas públicas e particulares quanto aos relatos. Foram realizadas entrevistas semi-estruturadas, com 47 docentes de escolas públicas e particulares. Nos relatos de violência na escola, predominaram as ações violentas praticadas pelos alunos e nos relatos de violência no bairro, predominaram as ações delinqüenciais. A relação triangular entre relatos, concepções de violência e práticas docentes indicou que os relatos confirmam, em certa medida, os resultados, tanto sobre as concepções de violência como sobre as práticas docentes. Embora tenham fornecido importante quadro complementar para a compreensão da concepção de violência dos professores, os relatos foram insuficientes para abarcar todas as dimensões desse conceito.
\end{abstract}

Palavras-chave: Violência; Relatos de episódios; Escola; Professoras.

\section{REPORTS ABOUT VIOLENCE, CONCEPTS OF VIOLENCE AND TEACHERS' CLASSROOM PRACTICES}

\begin{abstract}
This work aimed at analyzing the teacher's reports of violence events; to associate these reports to their concepts of violence and classroom practices, and to compare public and private schools teachers considering their reports. Forty seven public and private schools teachers were interviewed. According to the reports of violence events occurred in the school, the violent actions practiced by pupils were more common, and in the reports of violence in the neighborhood, the delinquency actions predominated. The triangular relation among reports, violence concept and teacher's practices indicated that those reports confirm somehow the results on the concepts of violence as well as on the teacher's practices. Although they have provided an important complementary picture to the understanding of teachers' violence concept, the reports were insufficient to meet all dimensions of this concept.
\end{abstract}

Key words: Violence; Reports of events; School; Teachers.

Vários estudos em Antropologia, Sociologia, Psicologia Social e Saúde Pública entendem a violência como um fenômeno socialmente construído. No âmbito dessas teorizações, Minayo (1994) trata a violência como um fenômeno biopsicossocial, mas cujo espaço de desenvolvimento é a vida em sociedade, podendo assumir formas peculiares em contextos sociais específicos.

\footnotetext{
1 Artigo recebido em 18/10/2005, aceito para publicação em 20/02/2006. 2 Endereço para correspondência: Liliane Viana de Souza, Rua Jair Santos, $\mathrm{n}^{\circ}$ 1, apto. 101, IAPI, Salvador, BA, CEP: 40330-460, Email: liliane.viana@pop.com.br
}

A literatura coloca a violência como um fenômeno de grande complexidade, sendo conceituado de diversas maneiras e a partir de distintas perspectivas. Num trabalho que aborda os problemas referentes à definição da violência, Ristum (2004b) observa que nos textos acerca do tema, encontra-se um amplo espectro de definições, das muito abrangentes às mais particularizadas, denotando polissemia do conceito, controvérsia na delimitação do próprio objeto, e difícil definição consensual.

Nessa mesma perspectiva, Waiselfisz e Maciel (2003) apontam duas questões que dificultam a 


\section{Liliane Viana de Souza}

conceituação da violência. A primeira refere-se ao fato de que os significados do termo violência são socialmente construídos, modificando-se de acordo com o momento histórico ou o contexto social. A segunda está relacionada ao fato de que a palavra violência pode se referir a situações bastante diversificadas, tais como a doméstica, juvenil, bélica, contra a criança, simbólica, que se associam a modos de manifestação e de entendimento diferentes.

Para Tavares dos Santos (2001) a violência surgiria como uma forma de sociabilidade, configurando-se como um mecanismo de controle social, aberto e contínuo. Nas suas palavras:

“A violência seria a relação social de excesso de poder que impede o reconhecimento do outro - pessoa, classe, gênero ou raça - mediante o uso da força ou da coerção, provocando algum tipo de dano, configurando o oposto das possibilidades da sociedade democrática contemporânea” (p.107).

Nos estudos acerca da violência escolar, adquire importância a questão da violência simbólica, conceito introduzido por Bourdieu (1998), que cria a possibilidade de consenso, sendo dessa forma utilizada como instrumento de dominação pelos representantes do poder na escola, entre os quais se coloca o professor.

O poder simbólico é quase mágico, permitindo obter através da palavra e do convencimento o que se consegue pela força física, e, portanto, sem gasto de energia (Bourdieu, 1998). Trazendo esse conceito para a realidade das instituições escolares, percebese o professor com um duplo papel: de um lado, como representante do poder - dominador - e de outro, o de dominado, submetendo-se a regulamentos e exigências burocraticamente estabelecidas.

Refletindo sobre a adjetivação da violência com o termo escolar, Ristum (2004a) propõe que se diferencie a que é engendrada nas especificidades das relações escolares e a que, apesar de acontecer nela, poderia ocorrer em qualquer outra situação social, não devendo, portanto, ser qualificada como escolar. Nesse sentido, ela abarcaria as ações protagonizadas por membros da escola (alunos, professores, diretores, funcionários) e realizadas com motivação pertinente às características e dinâmica desta instituição.

Sposito (1998) afirma que os significados do termo violência podem passar por alterações coeren- tes com o conjunto das ações escolares, com o seu contexto de produção e manifestação, sendo necessário investigar como aí são produzidas significações que designam e normalizam condutas violentas ou indisciplinadas por parte dos atores envolvidos.

O presente estudo adota como referencial a teoria histórico-cultural, que busca compreender a origem e o desenvolvimento dos processos mentais dos seres humanos. Nesta perspectiva, entende-se que a cultura torna-se parte da natureza humana, moldando o funcionamento psicológico, ao longo de um processo histórico; ressalta-se o caráter socialmente construído da subjetividade dos homens (Vygotsky, 1984, 1988).

No âmbito da proposta da Psicologia históricocultural, Vygotsky destaca, de acordo com Tunes e Simão (1998), a importância, para a pesquisa em Psicologia, de considerar os informes e interrogatórios verbais do sujeito. Essas autoras afirmam que o relato verbal, enquanto técnica de coleta de dados, pode ser tomado como representante da consciência dos indivíduos, permitindo o estudo de processos subjetivos a que somente o sujeito tem acesso. Nesse sentido, a pesquisa com relatos verbais possibilita uma análise objetiva dos fenômenos conscientes. Seguindo nessa argumentação, as autoras defendem que, durante o relato verbal, o sujeito seleciona dados da sua realidade, cabendo ao pesquisador organizar o conteúdo das falas, atribuindo-lhe significados, de forma a permitir a emergência de novos dados. Dessa maneira, a participação do pesquisador associa-se ao processo mais amplo da gênese social da consciência humana.

Em um estudo, em que foram analisadas as concepções de professores sobre processos de ensino-aprendizagem, através de relato verbal, Silva e Tunes (1999) apontam que o discurso deles está intimamente associado a sua ação em sala de aula e afirmam ser possível estudar o pensamento das pessoas através de sua fala que, nas condições reais de vida, não se separa de sua ação. Esta posição pode ser relacionada à tese de Vygotsky, conforme Lúria (1986), segundo a qual o pensamento se forma ou se realiza na linguagem.

Seguindo enfoque semelhante, Bruner (1997) defende a importância de se considerar, no estudo psicológico do homem, não apenas o que as pessoas fazem, mas também o que elas dizem e como expli- 
cam suas ações, principalmente, argumentando que uma Psicologia de orientação cultural deve partir da premissa de que dizer e fazer representam uma unidade funcionalmente inseparável.

No presente estudo assume-se que, com base nas proposições da teoria histórico-cultural, as falas dos sujeitos possibilitam o acesso a seus processos subjetivos, estando seus relatos verbais acerca de episódios violentos intimamente associados a suas concepções e ações frente a esta temática.

\section{Método}

\section{Objetivos}

A presente pesquisa pretende: 1) analisar os relatos de episódios de violência ocorridos na escola e no bairro, feitos pelas docentes; 2) relacionar os dados do presente trabalho ao conceito de violência destas professoras ${ }^{3}$; 3) relacionar os relatos de episódios de violência às práticas sociais e acadêmicas das professoras em sala de aula; 4) comparar escolas públicas e particulares quanto a esses objetivos. 5) adequar os relatos de violência para identificar o conceito de violência das professoras.

\section{Participantes}

Participaram do estudo 47 docentes do ensino fundamental, sendo 29 de escolas públicas e 18 de escolas particulares ${ }^{4}$.

A idade média das professoras era de 40 anos, o nível sócio-econômico médio-médio, de acordo com o bairro de residência e a classificação das próprias docentes. A maioria formou-se só no curso de magistério, exercendo a docência há cerca de 17 anos, não sendo observadas diferenças quanto às características pessoais dos dois grupos.

As escolas: Foram selecionadas quatro escolas de porte médio, de acordo com cinco critérios: a) duas deveriam pertencer à rede pública de ensino e duas, à particular, b) as quatro deveriam ter o primeiro segmento do ensino fundamental, estarem situadas em uma mesma região de Salvador, ter o primeiro grau de porte semelhante e a direção concordar

\footnotetext{
3 Comparando com dados de estudo anterior.

${ }^{4}$ Esta diferença no número de docentes de escolas públicas e particulares deveu-se a uma redução no número de classes de uma das escolas particulares, no período da coleta de dados.
}

com a realização do trabalho, permitindo o acesso aos professores.

\section{Procedimento}

Para a coleta de dados foi feita uma entrevista, em data e horário marcados pelas docentes, na própria escola, com base em roteiro semi-estruturado, composto de 22 questões referentes a diversos aspectos da violência, sendo que em duas era solicitado que elas relatassem episódios de violência vivenciados na escola em que trabalham ou em outras escolas, e no bairro em que residem. As entrevistas foram gravadas.

\section{Procedimentos de análise dos dados}

Inicialmente, foram selecionados, nas 47 entrevistas, todos os relatos de episódios de violência vivenciados pelas professoras na escola e no bairro; a seguir eles foram cuidadosamente lidos para a identificação de categorias elaboradas com base nos conteúdo das respostas, direcionadas pelos objetivos do trabalho.

Após a categorização dos dados, realizou-se a contagem de freqüência e cálculo de porcentagem, para facilitar a comparação entre professoras de escolas públicas e particulares e fornecer suporte para a análise qualitativa dos relatos, ao comparar o conceito de violência com práticas de sala de aula, vendo sua complementaridade.

\section{Resultados e Discussão \\ Relatos de violência escolar}

A Violência escolar (a que envolve membros da escola e refere-se a questões administrativas, disciplinares, acadêmicas, e de depredação escolar) foi relatada por 79,3\% das professoras de escola pública e por todas as de escola particular. Das que não se referiram a esta modalidade de episódio, três descreveram casos desvinculados das especificidades da dinâmica escolar, e três não mencionaram a questão.

Os episódios de violência escolar foram classificados em submodalidades estabelecidas considerando-se os atores sociais envolvidos (aluno e professor) e a direção da ação (de aluno para professor) (Ristum,2001 e Ristum e Bastos (2004).

Os dados acham-se na Tabela $1^{5}$.

\footnotetext{
${ }^{5}$ A categoria Não especificados abarca os relatos que não deixam claro entre quais membros ocorreu a violência e a direção da ação violenta.
} 
Tabela 1- Porcentagem de professoras de escola pública $(\mathrm{N}=29)$ e particular $(\mathrm{N}=18)$ que apresentaram nos seus relatos as sub-categorias da modalidade violência na escola.

\begin{tabular}{c|c|c|c}
\hline Violência na escola & $\begin{array}{c}\text { Professoras } \\
\text { de escola } \\
\text { pública (\%) }\end{array}$ & $\begin{array}{c}\text { Professoras de } \\
\text { escola } \\
\text { particular (\%) }\end{array}$ & $\begin{array}{c}\text { Total } \\
\text { (\% Média) }\end{array}$ \\
\hline Entre alunos & 65,5 & 83,3 & 74,4 \\
\hline De aluno para prof. & 24,1 & 22,2 & 23,1 \\
\hline $\begin{array}{c}\text { De agentes externos p/ } \\
\text { escola/ membros }\end{array}$ & 13,8 & 5,6 & 9,7 \\
\hline De prof. para aluno & 6,9 & 11,1 & 9,0 \\
\hline De aluno p/ func & 3,4 & 0,0 & 1,7 \\
\hline De aluno p/ a escola & 3,4 & 0,0 & 1,7 \\
\hline Não especificados & 0,0 & 5,6 & 2,8 \\
\hline
\end{tabular}

Os dados da Tabela 1 mostram que os casos de Violência entre alunos foram os mais relatados pelas professoras, seguidos dos de Violência de aluno para professor, porém com freqüência bastante inferior. Os episódios de Violência entre alunos aparecem com porcentagem maior no relato de professoras de escola particular e as formas mais encontradas foram: Briga, Agressão física e Agressão com arma branca ou objeto. A fala de uma professora de escola pública ilustra essa variedade:

“Eu já presenciei vários casos, na minha frente, assim, dentro da minha sala, um se pegar com o outro, bater, derrubar, esmurrar. Se pegam dois, vem mais dois, empurra e cai tudo lá” (P B12 e. pu.).

A Violência de aluno para professor tem porcentagem semelhante nas escolas públicas e particulares e as formas mais freqüentes foram: Agressão verbal e Assassinato. Vale ressaltar que os episódios de Coação, caracterizados pelo uso de algum tipo de poder para submeter ou subjugar pessoas, existiram somente entre professoras de escola pública, como o que se exemplifica a seguir:

"Um aluno de quinta série, com sintomas de que estivesse drogado, ameaçou a professora de português, não só dentro da escola como fora dela.(...) Ele disse que ia matar a professora, inclusive apareceu, dois ou três dias depois, com uma arma de fogo na escola” (P B11 e. pu.).

A Violência de agentes externos à escola ou a seus membros, mais relatada por professoras de escola pública, incluiu as modalidades: Agressão com arma de fogo (dois casos), Agressão com arma branca (um caso) e Roubo (um caso).
Poucas professoras se referiram à Violência de professor para com o aluno; a porcentagem maior aparece na escola particular, com as seguintes formas: Agressão verbal (dois casos), Agressão com arma branca (um caso); é interessante observar que somente uma falou do próprio comportamento.

“Até eu, ás vezes, me senti, que às vezes eu até agredi, reclamando, às vezes, chateada, até posso ter agredido, né?” ( $p$ C8, e par).

A Violência de aluno dirigida a funcionário aparece uma única vez, num episódio de Coação. Da mesma forma, a Violência de aluno à escola, modalidade que se refere à depredação, esteve presente no discurso de uma docente de escola pública. Ristum (2001) também constatou pequeno aparecimento desta categoria. Por ser um fenômeno freqüente nos estabelecimentos escolares públicos, era de se esperar que mais professoras se referissem a essa modalidade no seu conceito e a episódios de depredação escolar.

Quanto às Categorias de violência, foram identificadas: Violência de Delinqüência, Estrutural, de Resistência e de Resistência Deslocada, num trabalho realizado de acordo com as definições propostas por Minayo (1994) e Ristum (2001) ${ }^{6}$.

Tabela 2-Porcentagem de professoras de escola pública $(\mathrm{N}=29)$ e particular $(\mathrm{N}=18)$ que relataram casos de violência Estrutural, de Resistência Deslocada e de Delinqüência.

\begin{tabular}{c|c|c|c}
\hline Classes & $\begin{array}{c}\text { Professoras } \\
\text { de escola } \\
\text { pública (\%) }\end{array}$ & $\begin{array}{c}\text { Professoras de } \\
\text { escola } \\
\text { particular (\%) }\end{array}$ & $\begin{array}{c}\text { Total } \\
\mathbf{( \%} \\
\text { Média) }\end{array}$ \\
\hline Delinqüência & 62,1 & 61,1 & 61,6 \\
\hline Estrutural & 10,3 & 16,7 & 13,5 \\
\hline Resist. Desloc. & 3,4 & 0,0 & 1,7 \\
\hline Casos não clas & 31,0 & 66,7 & 48,8 \\
\hline
\end{tabular}

\footnotetext{
${ }^{6}$ Segundo a primeira autora, a Violência Estrutural é exercida pelas estruturas das instituições - família e sistemas econômicos, culturais e políticos que oprimem certos indivíduos, classes, grupos e nações, tornando-os mais vulneráveis ao sofrimento; a de Delinqüência é a que se manifesta nas ações fora da lei socialmente reconhecida e a de Resistência fica constituída pelas diferentes classes de respostas dos grupos, classes, nações e indivíduos oprimidos pela Estrutural. De acordo com a segunda autora, outra categoria, denominada Resistência Deslocada, foi acrescentada, e ela se refere às ações violentas que ocorrem como reação a situações de dominação, não dirigidas contra os opressores, mas deslocadas para situações em que a punição é menos provável.
} 
A maioria das docentes tanto de escola pública quanto privada relatou episódios de Violência de Delinqüência, em porcentagens bastante semelhantes, incluindo os tipos: Assalto e Assassinato, seguidos pelos de Violência Estrutural em que a porcentagem foi superior para as professoras de escola particular, tendo como base a praticada por policiais, que, no exercício de sua profissão, representam uma instituição do poder público, razão porque é dita Estrutural. A de Resistência Deslocada foi relatada por uma professora de escola pública, que se referiu a um episódio em que a empregada doméstica de sua vizinha, após ter roubado vários objetos e incendiado o apartamento da patroa, afirmou que sua ação foi motivada pela revolta por não possuir bens materiais como os de sua empregadora.

Por outro lado, cerca de metade das professoras relatou casos de violência com certas especificidades sendo necessário categorizá-los incluindo a Modalidade e a Forma. Segundo Ristum, 2001) dois são os critérios que definem a Modalidade: o status ou a posição social das pessoas envolvidas e a questão que foi o pivô da ação violenta. Os dados acham-se na Tabela 3.

Tabela 3- Porcentagem de professoras de escola pública ( $\mathrm{N}=29)$ e particular $(\mathrm{N}=18)$ que fizeram relatos de violência no bairro envolvendo cada modalidade

\begin{tabular}{c|c|c|c}
\hline Modalidade & $\begin{array}{c}\text { Professoras } \\
\text { de escola } \\
\text { pública (\%) }\end{array}$ & $\begin{array}{c}\text { Professoras de } \\
\text { escola } \\
\text { particular (\%) }\end{array}$ & $\begin{array}{c}\text { Total } \\
\mathbf{( \%} \\
\text { Média) }\end{array}$ \\
\hline De marginais & 48,3 & 55,6 & 51,9 \\
\hline Policial & 10,3 & 16,7 & 13,5 \\
\hline Entre pares & 10,3 & 16,7 & 13,5 \\
\hline Contra delinq. & 3,4 & 16,7 & 10,1 \\
\hline Contra si & 6,9 & 11,1 & 9,0 \\
\hline Entre vizinhos & 0,0 & 16,7 & 8,3 \\
\hline Passional & 13,8 & 0,0 & 6,9 \\
\hline Familiar & 3,4 & 5,6 & 4,5 \\
\hline Contra minor. & 3,4 & 5,6 & 4,5 \\
\hline Escolar & 3,4 & 0,0 & 1,7 \\
\hline No trânsito & 3,4 & 0,0 & 1,7 \\
\hline No trabalho & 3,4 & 0,0 & 1,7 \\
\hline Não especific. & 10,3 & 5,6 & 7,9 \\
\hline
\end{tabular}

A modalidade mais relatada foi a Violência de Marginais (cometida por bandidos, criminosos, forada-lei, dirigida a cidadãos, referente a atentados con- tra seus bens materiais, sua integridade física ou moral). A Violência Policial, entre Pares e Passional apresentaram porcentagens semelhantes e foram menos relatadas que a de Marginais.

É preciso notar que a Violência entre Pares e a Passional foram identificadas nos relatos do presente trabalho, mas não no de Ristum (2001), tendo sido definidas como: a que envolve amigos ou conhecidos, pessoas que ocupam posições equivalentes, e a que diz respeito a pessoas com vínculos afetivos, referente a motivações passionais.

As Formas de Violência foram categorizadas segundo o proposto por Ristum (2001). Encontraramse as formas: Assalto, Assassinato e Agressão física. A primeira está associada à Classe Violência de delinqüência e à modalidade Violência de marginais; foi a mais freqüente, e relatada por uma porcentagem superior de docentes de escola particular. A segunda mais freqüente, apontada por professoras de escola pública, aparece associada à de delinqüência e às modalidades de marginais, policial e passional. Já os casos de Agressão física, que remetem ao uso da força pelo agressor ao praticar a violência, estiveram mais presentes entre as professoras de escola particular.

A relação entre os relatos e o conceito de violência foi feita, de acordo com Ristum (2001), Ristum e Bastos (2004), e em separado para os de violência na escola e no bairro.

No que se refere aos episódios de violência na escola, a comparação aponta para os seguintes aspectos concordantes: a) as modalidades mais citadas pelas docentes foram a Violência entre alunos e a de aluno para professor; b) as docentes de escola pública e da particular se referiram à Violência de aluno para professor em porcentagens semelhante; c) mais professoras de escola pública relataram a Violência de agentes externos contra a escola ou seus membros. Já a Violência entre alunos e a de professor para aluno apareceram mais nos relatos das de escola particular.

Quanto à violência no bairro, a comparação aborda três categorias: classes, modalidades e formas. Na questão Classe, aparece, no relato da maioria das professoras, a Violência de Delinqüência. Lá a Estrutural foi colocada por poucas docentes, e, em especial pelas de escola particular, o que sugere 
terem elas maior consciência dos aspectos sociais relativos à violência

Com referência às modalidades de violência no bairro, foi identificada a presença da Violência de Marginais, como a mais freqüente, e a policial, apontada por professoras de escola particular.

Finalmente, no que diz respeito às formas, os dados concernentes a Assalto e Assassinato encontrados neste estudo, estão em concordância com os de Ristum (2001).

\section{Relação entre os relatos e as práticas das professoras}

Foram identificados três tipos de episódios: 1) de briga ou desentendimento entre alunos, 2) de dispersão, conversa, indisciplina, falta de atenção e 3) de brincadeiras de alunos pautadas pelo tema da violência.

Constatou-se que, frente aos episódios de briga ou desentendimento entre os alunos, delinearam-se diferentes quadros para as escolas públicas e particulares. Enquanto nas salas de aula dos estabelecimentos públicos foram mais freqüentes as ações repressivas (que incluem repreender, advertir ou ameaçar castigar, gritar ou falar em $\mathrm{voz}$ alta para parar, castigar fisicamente+, nas particulares houve uma clara superioridade das ações apaziguadoras, tais como pedir para parar, conversar/orientar os envolvidos, mudar ou mandar mudar de lugar. Percebeu-se, ainda, que a ação mais apresentada pelas professoras de escola pública foi a de ignorar (categoria - neutra), enquanto conversar/orientar (categoria - apaziguadora) foi a mais presente nas práticas dos estabelecimentos privados.

De acordo com Ristum (2001), as ações repressivas e apaziguadoras poderiam ser interpretadas como feitas com o objetivo de interromper episódios considerados perturbadores da ordem e do andamento da aula, não se podendo, portanto, afirmar que as brigas entre os alunos foram consideradas, pelas docentes, como formas de violência. Isto, assim como o ignorar, remete à questão da banalização da violência, presente em alguns dos relatos analisados, em que foi possível notar que, embora as professoras se referissem a ela entre alunos, ao serem solicitadas a falar dos episódios violentos ocorridos na escola, elas demonstravam considerar o termo muito forte para qualificar as agressões dos alunos em sala de aula, como exemplificam os trechos seguintes:

"Eu acho essa palavra tão forte (violência) pra
gente relatar um episódio de um menino no re-
creio, um tapa, uma palavra mais agressiva... por-
que eu acho que violência é assim, quando tem
sangue, tiro, faca" (professora C6, escola parti-
cular).

“... a violência entre eles é murro. Eu acho que essa violência já é o dia-a-dia deles. Mas outro tipo de violência, de arma, isso eu nunca vi" (professora B5, escola pública)

É possível, portanto, notar certa banalização presente no discurso das professoras, o que permeia e se imbrica nas suas práticas sociais e acadêmicas em situação de sala de aula.

Diante de episódios de dispersão, conversa, indisciplina, falta de atenção, as ações mais freqüentes, tanto para as de escola pública como particular, foram as ações repressivas (por exemplo, reclamar, advertir/ameaçar castigar, gritar). Destaca-se a baixa frequiência de ações orientadoras que seriam, segundo Ristum (2001) as mais compatíveis com a função formadora da escola. Ações repressivas podem ser relacionadas a relatos de episódios de Violência de professor para aluno, presente no discurso de poucas docentes. Esta comparação aponta, mais uma vez, para a normalização e banalização da violência no âmbito da instituição escolar.

Coerentemente com estas considerações, a ação de castigar fisicamente, tal como empurrar, dar tapa ou beliscão, puxar o cabelo e bater com régua, aparece apenas nas falas de professoras de escola pública, categorizados como Violência de professor para aluno. Visto que os castigos físicos ocorreram nos estabelecimentos públicos, poder-se-ia esperar que este fato se refletisse nos relatos de violência na escola, mas isso não aconteceu; então, supõese que estes episódios não são qualificados como violentos, mas concebidos como medidas educativas ou ações disciplinadoras.

Segundo Ristum (2001), diante dos episódios de brincadeiras pautadas pelo tema violência, houve um predomínio da ação de ignorar, ou seja, das ações neutras, para ambos os grupos de profes- 
soras. Este achado indica que, em metade das ocorrências, estas brincadeiras não foram vistas como importantes pelas docentes, quanto ao significado que pudessem ter no âmbito da violência.

Leontiev (1988), ao se referir às brincadeiras do período pré-escolar, nas quais, geralmente, há a presença de uma situação imaginária, destaca que as ações da criança, no brinquedo, são sempre reais e sociais e, a partir daí, ela assimila a realidade humana.

Carvalho e Pedrosa (2002) colocam que as crianças comumente trazem, para brincadeira, valores e conceitos da macrocultura compartilhada, estabelecendo, então, uma oportunidade de questioná-los, reconstruí-los ou fortalecê-los, dependendo da interação com os pares. Estas considerações apontam para a importância do brinquedo no desenvolvimento da criança, bem como para o fato de que os valores e conceitos da realidade sócio-cultural na qual ela se insere permeiam suas brincadeiras.

Nos relatos de episódios de violência, uma docente (de escola pública) referiu-se à brincadeira dos alunos, narrando episódios ocorridos durante o recreio, finalizando com o seguinte comentário: "até a brincadeira deles é violenta”. Nota-se, aí, uma reprovação, e não atenção ou preocupação quanto ao efeito que isto possa ter no desenvolvimento dos alunos.

Nos registros das observações, identificaramse comentários feitos pelas professoras sobre os alunos, que foram categorizados em reprovadores, elogiosos e pejorativos. As duas primeiras categorias indicam que elas avaliam o comportamento deles como adequados ou não, explicitando sua aprovação ou desaprovação. A última categoria (pejorativo) indica a depreciação ou chacota do aluno como característica principal (Ristum, 2001). Os dados obtidos mostram uma distribuição semelhante para os dois grupos, sendo bem superior a porcentagem de comentários reprovadores, vindo, em segundo lugar, os elogiosos e, por último, os pejorativos.

A despeito da predominância dos comentários reprovadores e da presença de pejorativos nas práticas das docentes, apenas uma pequena parcela trouxe episódios de Violência de professor para aluno, e só uma professora de escola particular se referiu ao próprio comportamento. As de escola pública, que fizeram mais comentários reprovadores e pejorati- vos (caracterizados pela depreciação do aluno), contraditoriamente, relataram episódios relacionados à referida modalidade em porcentagem inferior à das docentes de escola particular. Estes dados sugerem que as docentes não relacionam suas práticas de repressão e críticas depreciativas à questão da violência no âmbito da instituição escolar, indicando novamente os efeitos da banalização.

\section{Considerações finais}

As relações entre relatos e conceito: A análise dos relatos de violência na escola e sua comparação com o conceito de violência apontam para a conclusão de que a noção das professoras está relacionada, em geral, aos episódios que envolvem os alunos, seja como vítimas ou agressores, enquanto que elas e as outras autoridades escolares dificilmente são postos como agentes da violência, o que concorda com grande parte dos dados na literatura (Cardia, 1997; Lucinda, Nascimento \& Candau, 1999; Sposito, 2001).

Os relatos de violência escolar dos docentes não incluíram situações em que diretores, supervisores, professores tenham exercido a violência simbólica sobre seus subordinados, o que confirma dados da pesquisa de Ristum (2004b), ao mesmo tempo em que contradiz a visão de muitos pesquisadores.

A análise dos relatos de episódios violentos ocorridos no bairro, e a sua comparação com o conceito de violência, revelaram a predominância de ações delinqüenciais nas concepções das docentes, uma vez que os episódios mais freqüentemente relatados se referiram à classe Violência de delinqüência, à modalidade Violência de marginais e às formas Assalto e Assassinato.

A comparação entre relatos e conceitos possibilitou compreender algumas limitações da sua utilização para investigar a conceituação de violência. A estrutural apareceu no conceito de grande porcentagem das professoras, mas houve certa restrição à policial, o que sugere que ela tende a se incorporar ao cotidiano das pessoas de forma sutil, não sendo percebida em episódios concretos. Já a delinqüencial, relatada pela maioria das professoras, mesmo não fazendo parte do cotidiano das pessoas e tendo um caráter episódico, produz mais impacto e é mais percebida. 


\section{Sobre as relações entre relatos e práticas}

A comparação entre os relatos de episódios de violência vivenciados pelas docentes e as suas práticas em sala de aula destaca a presença da banalização. Observou-se que a normalização da violência, evidenciada em algumas falas, permeia e produz efeitos sobre suas práticas; isto confirma a colocação de Ristum (2001) de que o processo de banalização torna o conceito de violência cada vez mais limitado, de forma a não incluir ações, muitas vezes incorporadas ao cotidiano, e que são os primeiros degraus da escalada da violência.

No que se refere às práticas das professoras, destaca-se o predomínio de ações repressivas e comentários reprovadores para ambos os grupos, o que estaria relacionado à Violência de professor para aluno. Estes dados corroboram a afirmação de que a noção de violência escolar das docentes pesquisadas envolve principalmente a que tem, como primeiro agente, o aluno. Por outro lado, elas não percebem suas ações repressivas e seus comentários reprovadores como violência, ou seja, não se vêem como protagonistas dela, mas fazendo uso destas práticas como medidas educativas e disciplinadoras.

Apesar da dificuldade de comparação entre os relatos e as práticas foi possível aproximá-los, o que permitiu reafirmar e complementar alguns aspectos da concepção de violência das docentes, presentes tanto na sua fala como nas ações.

As comparações e análises realizadas permitem afirmar que relatos e ações se complementam na concepção de violência das docentes. Tunes e Simão (1998) consideram que as respostas verbais do sujeito apontam para aspectos da sua consciência, relativos àquela experiência. Seguindo esta perspectiva, afirma-se que as falas das participantes da presente pesquisa possibilitaram o acesso a seus pensamentos e concepções acerca da violência, e, na medida em que, eles não se separam dicotomicamente das ações cotidianas (Silva \& Tunes, 1999), pode-se relacionar o dito com as práticas em sala de aula.

Baseando-se nas formulações da teoria histórico-cultural, presume-se que a concepção de violência das docentes pesquisadas, presente tanto no seu discurso como nas práticas, é fruto de uma construção sócio-histórica-cultural. Dessa forma, a noção de violência destas professoras relaciona-se à realidade social e cultural na qual elas se inserem. E, as de escolas particulares trazem uma visão sócio-estrutural da violência mais acentuada que as da rede pública que, por sua vez, evidenciam, nos seus conceitos e relatos, reflexos de muitas dificuldades presentes no seu cotidiano pessoal e profissional; sim, várias diferenças encontradas entre os dois grupos podem ser associadas às características do seu ambiente de trabalho (localização da escola, perfil da clientela atendida, características do sistema de ensino, valorização profissional).

\section{Referências Bibliográficas}

Bourdieu, P. (1998). A economia das trocas simbólicas. São Paulo: Perspectiva.

Bruner, J. (1997). Atos de significação. Porto Alegre: Artes Médicas.

Cardia, N. (1997). A violência urbana e a escola. Contemporaneidade e Educação, 2 (2), 26-69.

Carvalho, A. M. \& Pedrosa, M. I. (2002). Cultura no grupo de brinquedo. Estudos de Psicologia, 7 (1), 181-188.

Leontiev, A. N. (1988). Os princípios psicológicos da brincadeira pré-escolar. Em L. S. Vygostky; R. Lúria \& A. N. Leontiev. Linguagem, desenvolvimento e aprendizagem (pp.119-142). São Paulo: Editora Î́cone.

Lucinda, M. C.; Nascimento, M. G. \& Candau, V. M. (1999). Escola e violência. Rio de Janeiro: DP\&A.

Luria, A. P. (1986). Pensamento e linguagem: as últimas conferências de Luria. Porto Alegre: Artes Médicas.

Minayo, M. C. (1994). A violência social sob a perspectiva da saúde pública. Cadernos de Saúde Pública, 10 (1), p. 07-16.

Ristum, M. (2001). O conceito de violência de professores do ensino fundamental. Tese de Doutorado, FACED-UFBa.

Ristum, M. (2004a). Problemas na conceituação e na circunscrição da violência: implicações metodológicas. Texto apresentado como parte 
da mesa-redonda intitulada: Questões conceituais e metodológicas no estudo da violência. XXXII Reunião Anual da Sociedade Brasileira de Psicologia, Ribeirão Preto - SP.

Ristum, M. (2004b). Violência: uma forma de expressão da escola? Aprender - Caderno de Filosofia e Psicologia da Educação, 2.

Ristum, M. \& Bastos, A. C. S. (2004). Violência Urbana: uma análise dos conceitos de professores de ensino fundamental. Ciência e Saúde Coletiva, 9 (1), 225-239.

Silva, E. G. \& Tunes, E. (1999). Abolindo mocinhos e bandidos: o professor, o ensinar e o aprender. Brasília: Editora da Universidade de Brasília.

Sposito. M. P. (1998). A instituição escolar e a violência. Cadernos de pesquisa, n. 104, 58-75.

Sposito, M. P. (2001). Um breve balanço da pesquisa sobre violência escolar no Brasil. Educação $e$ Pesquisa, 27 (1), 87-103.

Tavares dos Santos, J. V. (2001). A violência na escola: conflitualidade social e ações civilizatórias. Educação e Pesquisa. 27 (1). 105-122.

Tunes, E. \& Simão, L. M. (1998). Sobre análise do relato verbal. Psicologia USP, 9 (1). 303-324.

Vygotsky, L. S. (1984). A Formação social da mente. Martins Fontes: São Paulo.

Vygotsky, L. S. (1988). Aprendizagem e desenvolvimento intelectual na idade escolar. Em L.S. Vygotsky; A.R Luria \& A.N. Leontiev. Linguagem, desenvolvimento e aprendizagem. (pp.103-107). São Paulo: Ícone.

Waiselfisz, J. \& Maciel, M. (2003). Revertendo violências, semeando futuros: avaliação do Programa Abrindo Espaços no Rio de Janeiro e em Pernambuco. Brasília: Unesco.

Apoio financeiro: o trabalho foi realizado no período em que a primeira autora foi bolsista de Iniciação Científica - CNPq. 